\title{
Uma nova espécie de Phalloniscus Budde-Lund, 1908 (Crustacea, Oniscoidea) do sul do Brasil
}

\author{
Cristina M. L. Zardo 1
}

\begin{abstract}
A new species of Phalloniscus Budde-Lund, 1908 (Crustacea,Oniscoidea) is described: Phalloniscus 1 oyolai sp.n. from Curitiba, Paraná, Brazil.

De acordo com LEMOS DE CASTRO, 1960 o gênero Phalloniscus BuddeLund, 1908, foi instituido sem apresentação de diagnose, abrigando duas espécies de iśopodos da Nova Zelância incluídas, até então, no gênero Oniscus Linnê, 1755.

VENDEL, 1952 discute a validade e estabelece a diagnose do gênero, considerando sua distribuição na América Tropical para a Venezuela, Bolívia, Trinidad e Guianas.

VANDEL, 1962 e LEMOS DE CASTRO (com. pes.) propõem uma revisão de todas as espécies atribuídas ao gênero, para uma possível ordenação, talvez em diferentes gêneros afins.

O presente trabalho tem como finalidade a descrição de uma espécie nova da Phaolloniscus, sendo esta, a sexta espécie registrada para o Brasil e a décima segunda para a América, significando também, a ampliação da distribuição geográfica do gênero para o Brasil.
\end{abstract}

\section{Phalloniscus loyolai sp.n.}

(Figs. 1-25)

Diagnose: Endopodito do primeiro par de pleópodos do macho estreito, afilando-se gradualmente para o ápice e, da metade em diante, estiliforme, com a ponta aguda;subapicalmente com uma série de cerdas pequenas, na margem interna. Carpos do primeiro e do segundo par de pereiópodos, com maior densidade de cerdas que dos outros pares. Exopodito dos primeiros pares de plébodos ovóides, contendo área respiratória especializada. Olhos compostos de cinco omatídios. Bolsa incubadora, das fêmeas ovígeras, medindo, em média, 1,2 mm. Comprimento do corpo, dos machos adultos, de 2,5 mm e, das fêmeas ovígeras, de 3,2 mm.

1. Departamento de Ciências Morfobiológicas da Universidade do Rio Grande. Caixa Postal, 474 96200 Rio Grande - RS 
Descrição: Holótipo macho. Corpo de forma ovalada, com 2,5 mm de comprimento e $1,0 \mathrm{~mm}$ de largura, no quinto segmento torácico. Coloração marromclara com manchas esbranquiçadas espalhadas pela cabeça e corpo. Cabeça larga em relação ao corpo, com lobos laterais levemente desenvolvidos. Linha frontal presente e bem marcada.Olhos pequenos e não salientes, compostos por cinco omatídios. Pleuroepimeros pouco desenvolvidos. Ângulos ântero-laterais do primeiro segmento torácico pouco desenvolvidos. Há um estreitamento gradual do tórax para o abdome. Neopleurons dos terceiro, quarto e quinto segmentos com os ângulos posteriores alongados, com ápice arredondado.Telso triangulado e curto em relação à largura, com o ápice amplamente arredondado. Primeiro par de antenas curto e triarticulado. Segundo par de antenas, quando distendido ao lado do corpo, alcançando a metade do segundo segmento torácico. Flagelo antenal triarticulado, sendo o primeiro artículo o mais curto. Mandíbulas robustas, com incisor fortemente quitinizado. Mandíbula esquerda com incisor tricúspide e lacínia bicúspide seguida por um lobo cerdoso, provido de um penicílio e um tufo de cerdas longas. Mandíbula direita com incisor quadricúspide e lacínia quadrangulada seguida de dois penicílios e um tufo de cerdas longas. Primeiro par de maxilas com o ramo externo mais longo e largo que o interno. $\mathrm{O}$ ramo externo apresentando na margem externa, uma leve concavidade e uma série de cerdas na região basal. Na margem distal presentes oito cerdas, sendo as quatro internas, afiladas e de extermidade aguda; das quatro externas, três saó mais engrossadas e uma com a metade do comprimento das outras, todas com o ápice rombudo. Segundo par de maxilas laminar, com a margem distal bilobada. Endito interno do maxilípede laminar, quadrangulado e apresentando uma longa cerda na face ventral; palpo triarticulado com várias cerdas. Pereiópodos semelhantes entre si, com o carpo do primeiro e do segundo par, com maior concentração de cerdas que nos outros artículos. As cerdas, nos outros perei6podos, uniformemente distribuídas nos três últimos artículos. Primeiro e segundo par de pleópodos com endopodito estiliforme. $\mathrm{O}$ endopodito do primeiro par estreito, afilandose gradualmente em direção ao ápice, da metade para diante estiliforme, de ponta aguda, apresentando na margem interna, subapicalmente, uma série de pequenas cerdas. O endopodito do segundo par de pleópodos muito estreito com ponta afilada e longa. Exopodito do primeiro par de plébpodos ovalado e dos outros pares triangulados. Exopoditos dos primeiro e segundo pares de plé́podos com área respiratória. Urópodos com endopodito em forma de bastão e exopodito lanceolado com cerdas no ápice.

Tipo e Localidade-tipo: Holótipo macho de Curitiba - Paraná, Parque Barigui, 29/X/82, MZUSP-9703, ZARDO, C.M.L. col. Parátipos com os mesmos dados do Holótipo: 1 macho, MZUSP-9704; 11 fêmeas, MZUS P-9705.

Dados Ecologicos: Espécie encontrada no Parque Barigui (Curitiba, Paraná, Brasil), local onde se mantem a vegetação nativa. Os espécimes foram coletados sob folhas caídas e apodrecidas, misturadas com o solo, ao redor do tronco de árvores.

Comentário: A espécie Phalloniscus loyolai sp.n. assemelha-se a P. marcuzzi Vandel , 1952 pela forma dos plé́podos e pelo flagelo antenal. Distingue-se por apresentar menor comprimento do corpo, lobos laterais da cabeça menos desenvol- 

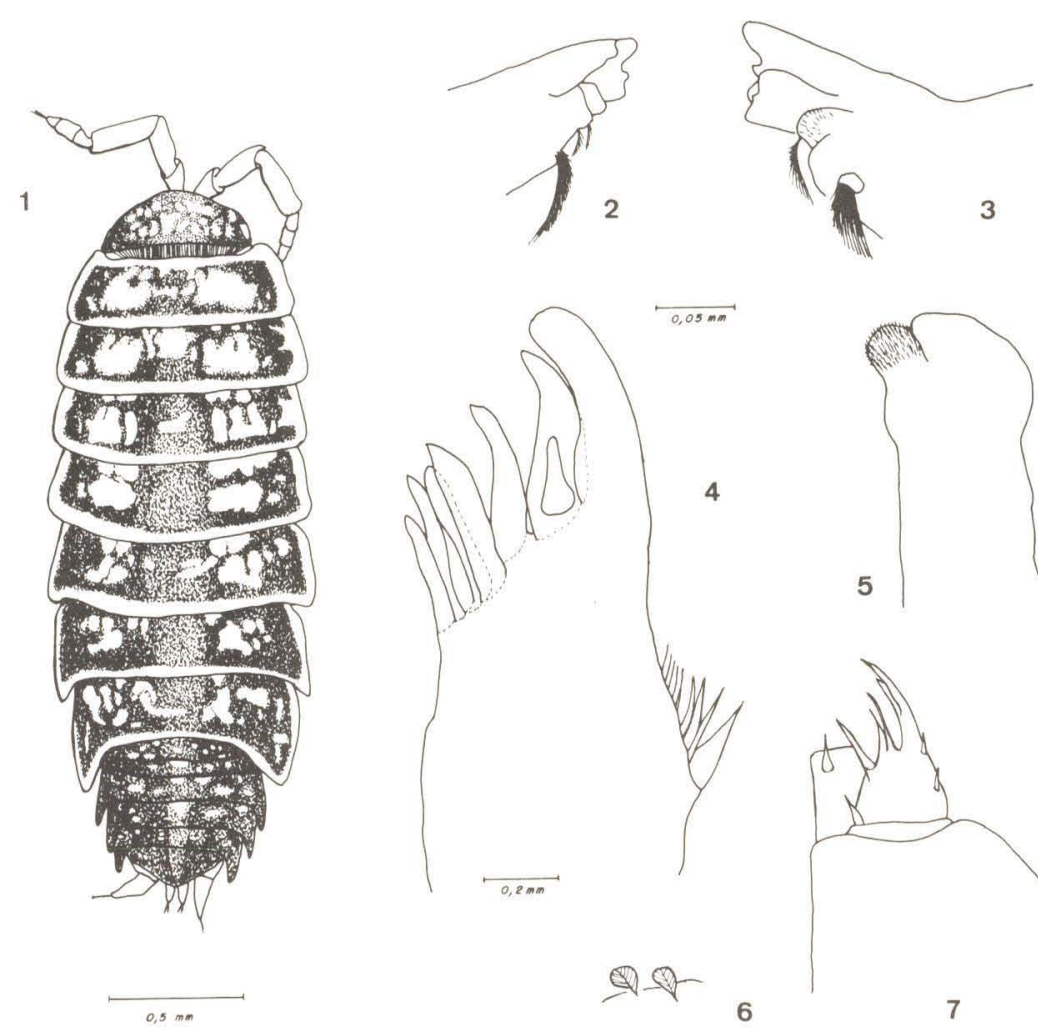

4
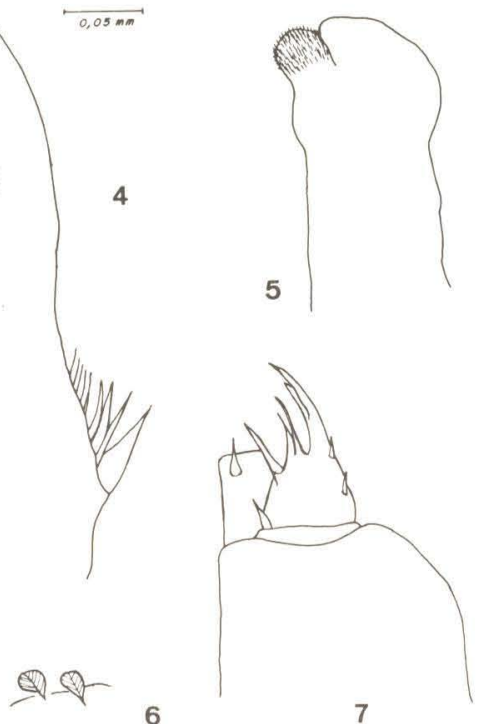

Figs. 1-7. Phalloniscus loyolai sp.n., macho. 1, vista dorsal; 2, mandíbula direita; 3, mandíbula esquerda; 4 , ramo externo da primeira maxila; 5 , segunda maxila; 6 , cerdas da cabeça; 7 , maxilípede.

vidos e ápice do telso amplamente arredondado. Assemelha-se também a $P$. dissimilis Lemos de Castro , 1960 pela forma da cabeça e dos lobos laterais; pelo pequeno tamanho dos olhos e número reduzido de omatídios; pela característica do primeiro artículo do flagelo antenal ser mais curto que os demais; e pela forma geral do abdome e neopleurons. Mas, $P$. loyolai sp.n. e $P$. dissimilis podem ser diferenciados, pela forma dos maxilípedes; pela forma da extremidade do endopodito e forma do exopodito do primeiro par de plépodos do macho. $P$. loyolai sp.n. pode ser comparada a $P$. setosus Lemos de Castro , 1960 pelo segundo par de maxilas e maxilípedes. Nítida diferenciaçaõ pode ser feita pela forma da cabeça; pelo comprimento dos artículos do flagelo antenal; pelo número de ocelos; pelo tamanho e aspecto dos olhos; pela extremidade do endopodito do primeiro par de pleópodos do macho; e forma da extremidade do telso. 


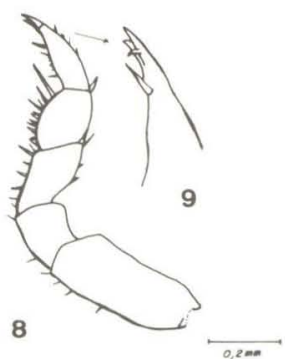

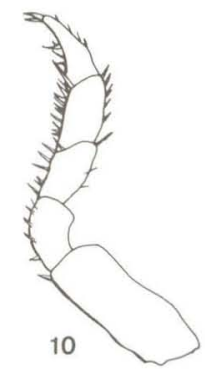

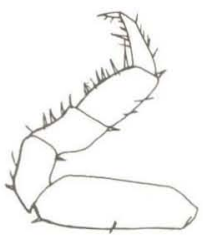

11

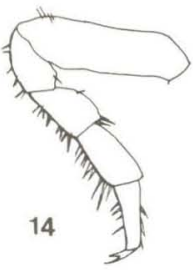

15
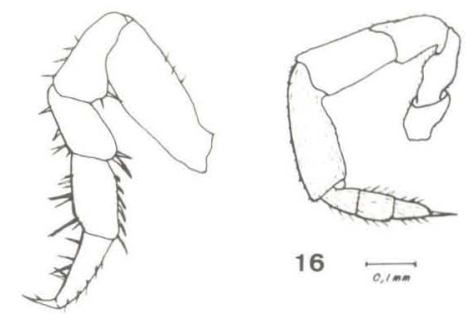

16

12
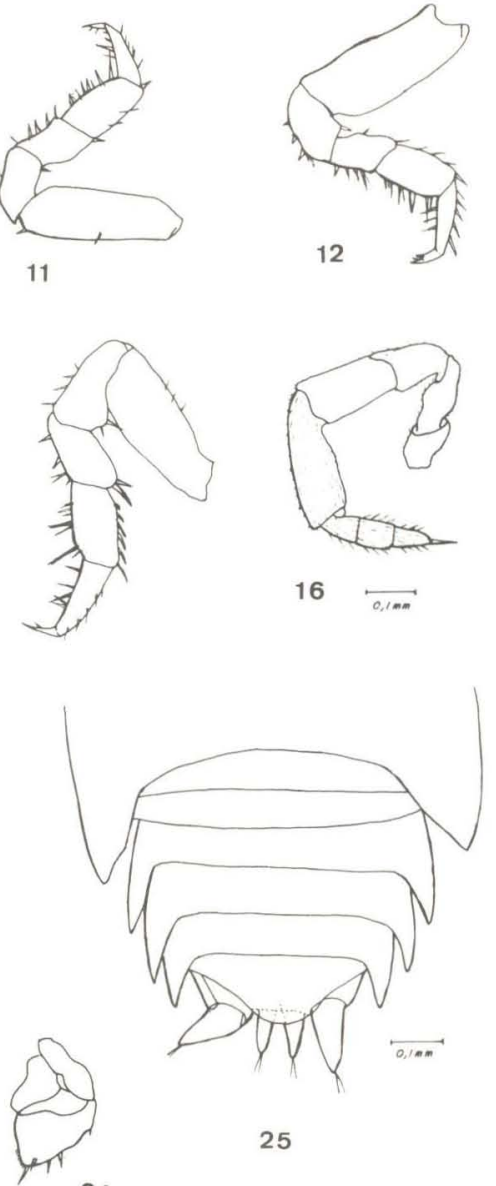

24

Figs. 8-25. Phalloniscus loyolai sp.n., macho. 8, primeiro pereiópodo; 9 , dáctilo do primeiro pereiópodo; 10, segundo pereiópodo; 11 , terceiro pereiópodo; 12, quarto pereiópodo; 13, quinto pereí́podo; 14, sexto pereí́podo; 15, sétimo pereiópodo; 16, segunda antena; 17 , endopodito do primeiro pereí́podo; 18 , exopodito do primeiro pleópodo; 19 , extremidade do endopodito do primeiro pléspodo; 20 , endopodito do segundo plébodo; 21, exopodito do segundo plé́podo; 22, terceiro plé́podo; 23, quarto pleópodo; 24 , quinto pleópodo; 25 , abdome em vista dorsal.

$P$. loyolai sp.n. tem similaridade com $P$. singularis Lemos de Castro , 1967 pelo aspecto geral do corpo, contudo pode ser diferenciada por não possuir esporão na margem do endopodito do primeiro par de plébpodos do macho e pela estrutura dos maxilípedes. Apresenta afinidades também com $P$. minimus Van- 
del , 1977 devido ao pequeno comprimento do corpo, mas diferenciam-se pela estrutura do primeiro par de pleópodos do macho e pelo número de omatídi os.

Embora sendo $P$. loylai sp.n. uma espécie que apresenta similaridades com várias outras, a característica dos plé́podos do primeiro par dos machos, considerada por VANDEL, 1977 como excelente critério que permite distinguir as espécies de Phalloniscus, pode ser comparada entre todas as espécies, além de outras características.

O nome da espécie é dedicado ao Prof. Dr. Jayme de Loyola e Silva, Universidade Federal do Paraná, pela dedicação na orientação de nossos trabalhos.

\section{REFERÊNCIAS}

LEMOS DE CASTRO, A. 1960. S obre as espécies americanas de Phalloniscus Budde-Lund (Isopoda, Oniscoidea), com descrição de quatro espécies novas. Actas y trabajos del Primer Congreso Sudamericano de Zoologia , 2: 203-211.

VANDEL, A. 1952. Étude des Isopodes terrestres récoltés au Vénézuela par le Dr. G. Marcuzzi, suivie de considerations sur le peuplemente du Continent de Gondwana. Mem. Mus. Civ. Stor. Nat. Verona, 3: 135-145.

VANDEL, A. 1962. Isopodes Terrestres (Deuxieme partie). pp. 417-931. In: Faune de France vol. 66 Paris. Ed. P. Lechevalier.

VANDEL, A. 1977. Les Oniscoides (Isopodes Terrestres) de la Nouvelle ZÉlande et de L'Archipel Kermadec. Mem. Mus. Nat. Hist. nat, Paris, Série A, Zoologie, 102: 11-16. 